\title{
Anclajes territoriales en un espacio de borde: el caso del rururbano de la ciudad de Bahía Blanca (Buenos Aires, Argentina) $)^{1}$
}

\section{TERRITORIAL ANCHORING IN THE FRINGE: THE CASE OF THE RURURBAN AREA OF BAHÍA BLANCA (BUENOS AIRES, ARGENTINA)}

ANCORAGENS TERRITORIAIS EM UM ESPAÇO PERIFÉRICO: O CASO DA ÁREA RURURBANA DA CIDADE DE BAHÍA BLANCA (BUENOS

AIRES, ARGENTINA)
Para citar este artículo: Sereno, C. (2020). Anclajes territoriales en un espacio de borde: el caso del rururbano de la ciudad de Bahía Blanca (Buenos Aires, Argentina). Perspectiva Geográfica, 25(2) 56-79. https://doi.org/10.19053/01233769.11032
Recepción:

22 de mayo de 2020

Evaluación:

16 de julio de 2020

Aprobación:

30 de julio de 2020

\section{Resumen}

En este trabajo se describen las características socioespaciales del rururbano de la ciudad de Bahía Blanca y también se detectan los anclajes territoriales de los residentes para comprender la manera en que estos se convierten en una fortaleza

1 Este trabajo se realizó en el marco del proyecto "Los espacios locales y regionales como una construcción socio-cultural. Análisis multiescalar", financiado por la Secretaría de Ciencia y Tecnología de la Universidad Nacional del Sur, y forma parte de la tesis doctoral Procesos socioambientales en un espacio del borde. Estrategias de los actores en el rururbano bahiense (2017).

2 Doctora en Geografía, título otorgado por la Universidad Nacional del Sur, Bahía Blanca, Argentina. Además, forma parte d el plantel docente del Departamento de Geografía y Turismo de la Universidad Nacional del Sur, Bahía Blanca, Argentina. Correo: csereno@uns.edu.ar. Orcid: https://orcid.org/0000-0002-2986-6807. 
para permanecer en este ámbito y condicionan las estrategias para enfrentar las presiones urbanas que los exponen a distintos cambios y al riesgo de perder su propiedad. La metodología se sustenta en el trabajo de campo experiencial a través de observaciones y la aplicación de entrevistas semiestructuradas a los residentes del área, así como en el análisis temático y contextual de los datos recolectados. En este marco, se corrobora la relación entre aquellos residentes que presentan un fuerte anclaje territorial con la menor disposición al cambio y la implementación de estrategias de permanencia para conservar sus propiedades y sus actividades.

Palabras clave: anclaje territorial, estrategias de permanencia, presiones urbanas, rururbano.

\section{Abstract}

This paper describes the socio-spatial characteristics of the rururban area of Bahía Blanca. It detects the residents' territorial anchoring to understand how it becomes a stronghold to stay there and conditions the strategies to face the urban pressures that expose them to changes and the risk of losing their property. The method builds on experiential fieldwork through observations and semi-structured interviews with locals and the thematic and contextual analyses of the data collected. The results corroborate the relationship between those residents who have robust territorial anchoring and are less willing to change and the implementation of occupancy strategies for retaining their properties and activities.

Keywords: Territorial anchoring, occupancy strategies, urban pressures, rururban.

\section{Resumo}

Neste trabalho, descrevem-se as características sócio-espaciais do rururbano da cidade de Bahía Blanca e também são detectadas as ancoragens territoriais dos moradores para compreender a maneira como estes se tornam numa fortaleza para permanecer nesta área e condicionam as estratégias para enfrentar as pressões urbanas que os expõem a diferentes mudanças e ao risco de perder sua propriedade. A metodologia baseia-se no trabalho de campo experiencial por meio de observações e aplicação de entrevistas semiestruturadas a os moradores da área, bem como na análise temática e contextual dos dados coletados. Nesse quadro, corrobora-se a relação entre os 
moradores que possuem uma forte âncora territorial com menor disposição para as mudanças e a implementação de estratégias de permanência para a conservação de seus bens e suas atividades.

Palavras-chave: ancoragem territorial, estratégias de permanência, pressões urbanas, rururbano.

\section{Introducción}

Las ciudades intermedias han sufrido un crecimiento importante en los últimos años, con los consecuentes impactos en las áreas rurales que se transforman en áreas de transición entre lo urbano y rural, en primera instancia, hasta ser urbanizadas totalmente. El rururbano, como uno de estos bordes, constituye la franja externa del periurbano ${ }^{3}$ y se caracteriza por la heterogeneidad —en sus paisajes, en los actores que la habitan o poseen intereses en ellos y en las formas de habitar estos espacios-, por presentar una dinámica propia - signada por las transformaciones que introduce en particular la urbanización - y por su complejidad (Barsky, 2005; Feito, 2018; Sánchez Ayala, 2015; Ballén-Velásquez, 2014).

De este modo se genera un ámbito que posee un ritmo singular, caracterizado por la interacción y la competencia entre múltiples intereses, usos del suelo y prácticas propias de un espacio de transición o "frontera"4 (Barros \& Zusman, 2001, p. 27). Esta

3 Si bien son escasos los autores que establecen una diferencia con el periurbano -incluso hay quienes los consideran sinónimos-, la distinción, aunque sutil, existe y es necesaria para los fines de esta presentación. Ver: González Plazas (2006); García Ramón et al. (1995); Zuluaga Sánchez (2005); Arango Escobar (2008); González Escobar (2003) y Ballén-Velásquez (2014).

4 El término frontera es objeto de interpretaciones diversas, de lascuales se seleccionan dosque aportana lacomprensión de las interacciones en el rururbano. Así, Reboratti (1990, p. 1) combinación de factores expone a la población rural, que prevalece en estos sitios, a situaciones de vulnerabilidad por presiones de diferente índole — tales como las que ejercen agentes inmobiliarios, las derivadas de políticas de planificación urbana y las de agentes de diversos sectores económicos como industrias $\mathrm{u}$ otras empresas que se interesan en estas tierras, entre otros- $-y$ al riesgo de perder sus propiedades.

Es necesario aclarar que algunas de las transformaciones en las periferias responden al proceso de globalización que también impacta en este ámbito, modifica las relaciones campo-ciudad y permite que áreas agrícolas adquieran nuevas fisonomías a partir de procesos de urbanización del agro y del cambio tecnológico, así como también favorece el movimiento de habitantes urbanos que buscan sa-

menciona tres maneras de concebirlas: 1) desde el punto de vista político, como la "línea divisoria o el sector de un país" que lo diferencia de otros y que encierra el límite; 2) teniendo en cuenta aspectos sociales y culturales, al mencionar la frontera como el "borde exterior del asentamiento humano"; y, por último, 3) las identifica como un "área de confrontación entre diferentes pueblos". En esta línea, el rururbano concuerda con la segunda concepción, puesto que constituye el borde externo de la ciudad, pero también es un ámbito proclive al enfrentamiento entre modos de vida diferentes. Por otra parte, Arriaga Rodríguez (2012) se refiere al concepto como espacios socialmente construidos, un espacio vivido y apropiado a través de prácticas sociales y con una identidad propia. Tomando los aportes de este autor, el rururbano constituye una zona dúctil que se conforma como resultado de las acciones de sus residentes en su hacer cotidiano y de los vínculos que establecen, así como del avance poblacional y edilicio característico de estos escenarios. 
tisfacer sus necesidades en el campo y homogeniza modelos de organización del espacio geográfico (De Mattos, 1999; Martínez Borrego, 2006; Ávila Sánchez, 2009; García Ramón et al., 1995).

En consecuencia, cada residente adopta como respuesta distintas actitudes y estrategias, donde el anclaje territorial de cada uno - vinculado a la manera de apropiar el espacio, a los nexos con el lugar y con otros residentes del área, a la pertenencia y el significado de lugar forjado a través de las vivencias y las prácticas cotidianas - se convierte en una fortaleza para resistir los cambios y permanecer en el lugar conservando su actividad - en general, relacionada con tareas agropecuarias-.

En este marco, surgen preguntas vinculadas al estudio del rururbano de la ciudad de Bahía Blanca, tales como: ¿cuáles son las formas de habitar el rururbano bahiense? ¿Qué significados y vínculos se generan entre sus pobladores y con el lugar? ¿Qué lleva a los residentes rurales del área a permanecer a pesar de las presiones urbanas a las que están sometidos? ¿Qué anclajes territoriales existen? ¿De qué manera el anclaje territorial incide en las estrategias de los residentes?

La ciudad de Bahía Blanca se encuentra en el partido homónimo y está localizada en el sudoeste de la provincia de Buenos Aires (Figura 1). El partido de Bahía Blanca abarca una superficie de $2.300 \mathrm{~km}^{2}$ con una población de 301.572 habitantes (Instituto Nacional de Estadística y Censos, 2014). La actividad económica del entorno es considerada de perfil agrícola e industrial, además la ciudad cuenta con servicios culturales, administrativos y comerciales, entre otros que ofrece también para una extensa región circundante.

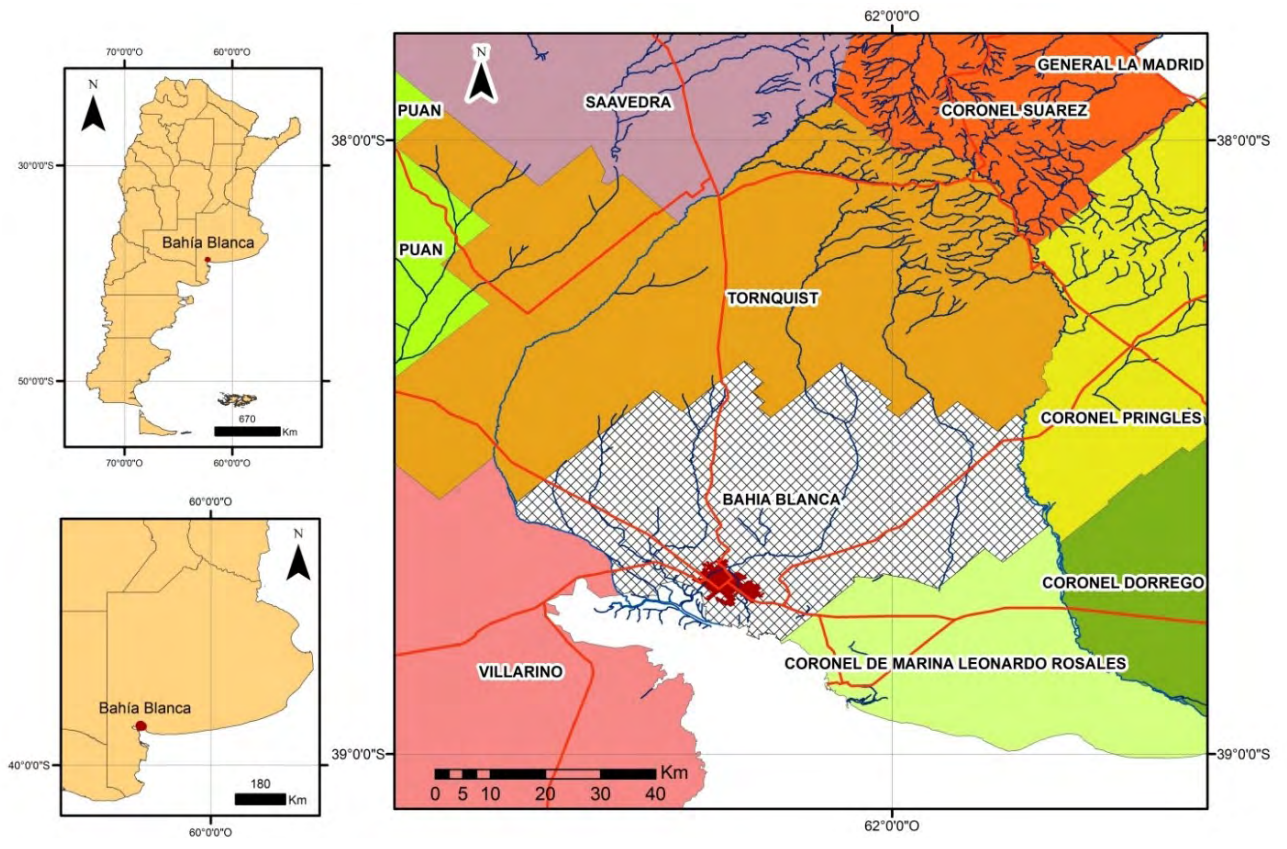

Figura 1. Localización de Bahía Blanca, provincia de Buenos Aires (Argentina)

Fuente: elaboración propia con base en el Atlas digital de recursos hídricos superficiales de la República Argentina (Instituto Nacional del Agua, 2002; mapa elaborado en 2017). 
Durante la década de 1970 y desde 1990, la ciudad experimenta un crecimiento de población notable - a expensas de atraer población de las localidades cercanas-y sufre, en consecuencia, alteraciones internas de sus elementos constitutivos y, en particular, de sus bordes, donde se observa una expansión del suelo urbano con una ocupación de baja densidad —entre 1991-2010 la superficie urbana ocupada creció un 89\% (Urriza, 2018)-. Es dable mencionar el impacto sobre el área del
Plan de Desarrollo local (Municipalidad de Bahía Blanca, 2009) y el Plan Director del Periurbano Bahiense (Municipalidad de Bahía Blanca, 2011) que crearon nuevos límites para el espacio urbano y el periurbano y, en consecuencia, reactivaron la ocupación de las periferias y del área de estudio en especial, pues queda incluida en una de las zonas con mayor aptitud para el crecimiento de baja densidad.

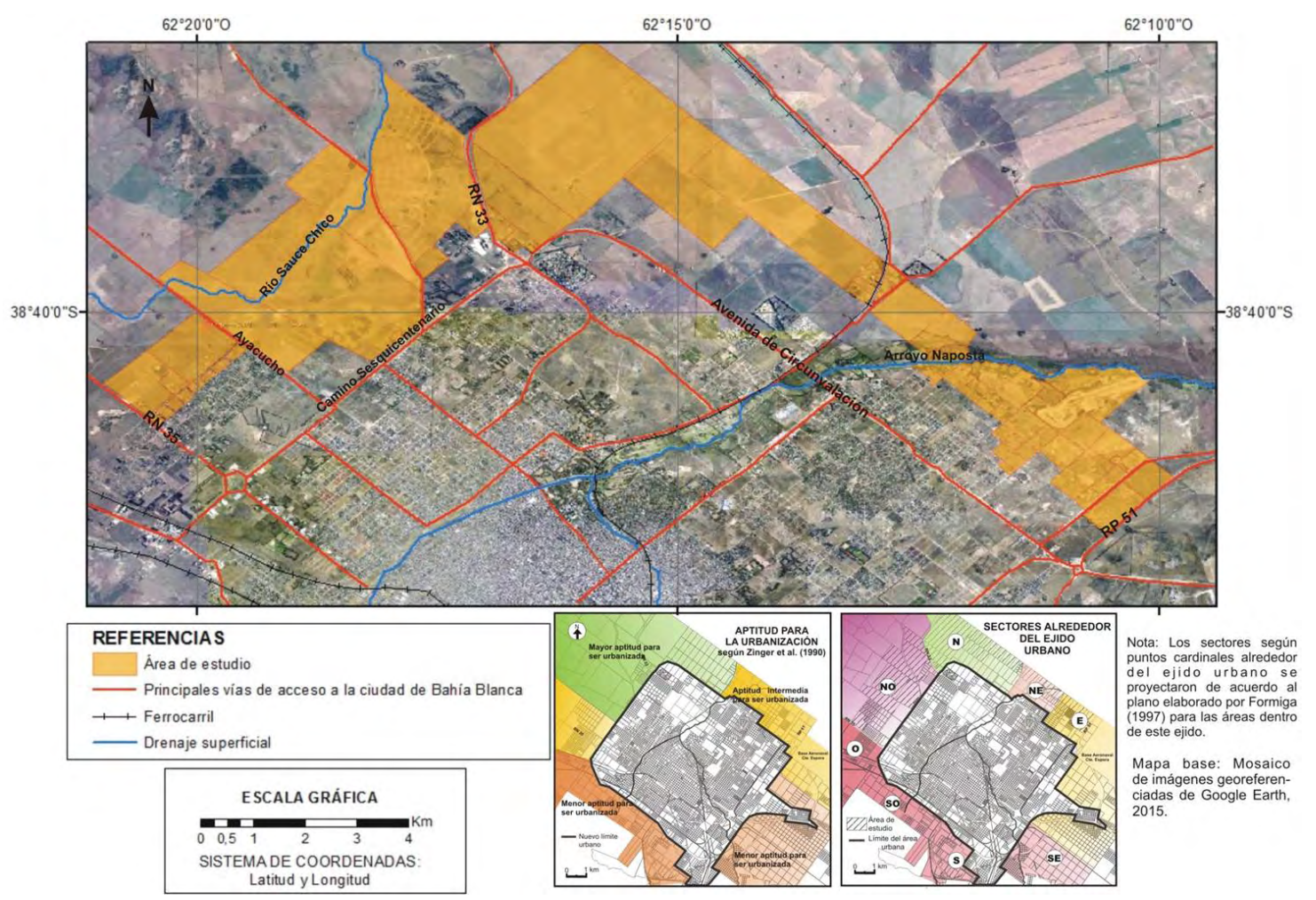

Figura 2. Localización del área de estudio

Fuente: elaboración propia (2017)

A este panorama deben sumarse los efectos de la tendencia a valorar espacios de transición y rurales que ha impulsado la elección de estos como lugar de residencia por los precios de los terrenos, la densidad de población baja y el contacto con la naturaleza (Urriza, 2003). El trabajo, entonces, tiene como área de estudio el rururbano de la ciudad de Bahía Blanca — en particular los sectores norte, 
noreste, noroeste y este ${ }^{5}$ del mismo (Figura 2)-, $\mathrm{y}$, como objetivos, busca describir las características socioespaciales de este ámbito — destacando no solo sus paisajes, sino las prácticas y rutinas que forman parte de la cotidianidad de este borde-, así como detectar los anclajes territoriales de los residentes, en especial de aquellos con mayor antigüedad, para comprender la manera en que estos se convierten en fortalezas a la hora de enfrentar las presiones urbanas.

\section{Metodología y técnicas}

La metodología cualitativa empleada para concretar el trabajo se basa en la aplicación de dos procedimientos principales: las entrevistas semiestructuradas y la observación directa. Así, se lleva adelante un trabajo de campo experiencial con el propósito de comprender la cotidianidad de este espacio y recuperar las narrativas espaciales y las perspectivas de los sujetos habitantes (Hiernaux \& Lindón, 2008; García Ballesteros, 1992).

En este marco, la entrevista constituye una herramienta apropiada para recuperar relatos y vivencias puesto que cada entrevistado recrea sus experiencias, expresa sus rutinas diarias y rescata lo simbólico y lo subjetivo para explicar la complejidad que reviste el objeto de estudio. El análisis de estas es temático, ya que se identifican categorías analíticas para su comparación entre los distintos actores del rururbano, y contextual, porque se propone una interpretación situada en el tiempo y el espacio y relacionada con los demás relatos del área de estudio.

5 Se seleccionan estos sectores porque poseen la mejor aptitud para el avance de la urbanización (Zinger et al., 1990). La sectorización del área de estudio se realizó sobre la base de la delimitación de Formiga (1997) con el propósito de facilitar la interpretación de los resultados.
Se realizaron 27 entrevistas: 23 a propietarios o arrendatarios dedicados a tareas agropecuarias intensivas, hornos de ladrillo, prestadores de servicios rurales y antiguos residentes del borde - es decir, aquellos dedicados a actividades cuya permanencia es difícil frente al avance urbano- y 4 a nuevos residentes del área.

El propósito de estas fue obtener información sobre prácticas y rutinas cotidianas, sentimientos y vínculos sociales, deseos y expectativas en relación con el espacio vivido, así como estrategias y percepción de los cambios, es decir, aspectos que permiten caracterizar el anclaje territorial de cada uno. La recopilación se efectuó mediante un muestreo teórico, no probabilístico, en el cual se combina la modalidad de "juicio experto" y "bola de nieve".

En relación con la observación directa en el terreno, se realizaron varias salidas de campo en cada sector del rururbano para reconocer el área y recabar información sobre los principales elementos naturales y sociales - es decir, tipo de ocupación, tipo y estado de caminos, infraestructura y usos del suelo, entre otros aspectos-.

\section{Anclaje territorial:}

\section{aproximaciones conceptuales}

El rururbano se concibe como un área de significados que despierta sentimientos y lazos de pertenencia cimentados en un proceso de múltiples experiencias cotidianas, es decir, un lugar que se vincula con lo afectivo y puede constituirse en un ámbito identitario para los residentes. De este modo, cada habitante - tanto del rururbano como de otros ámbitos-, a través del tiempo y en el ha- 
cer cotidiano, construye su anclaje territorial, que lo lleva a amar, defender, luchar por permanecer o desprenderse de su propiedad y alejarse de estos espacios apropiados desde las experiencias.

Si bien existen autores que emplean este concepto desde distintas perspectivas ${ }^{6}$, el presente trabajo considera indagaciones como las de Giddens, que introduce las nociones de anclaje y desanclaje entendidos en el contexto de la globalización: la primera está relacionada con la actividad social en contextos de presencia, en tanto que la segunda se vincula con " 'despegar' las relaciones sociales de sus contextos locales de interacción y reestructurarlas en indefinidos intervalos espacio-temporales" (1993, pp. 31-32). Asimismo, completa estas ideas con el concepto de reanclaje, entendido como "reapropiación o disposición de las relaciones sociales desvinculadas, para relacionarlas (aunque solo sea parcial y transitoriamente) a las condiciones locales de tiempo y lugar" (Giddens, 1993, p. 81).

Además, son valiosos los aportes de Jungemann (2008), Cañón (2014) y Avalle (2009), por mencionar algunos, que aplican el concepto para comprender las maneras en que se generan espacios de participación comunitaria en busca de reivindicación de derechos de distintos grupos sociales, pero conservando su identidad y su espacio propio. Así, definen el anclaje territorial como "la solidez de los fundamentos sociales con los que se basa un fenómeno y se emplaza en un territorio específico

6 Desde una visión económica, Frayssignes (2005) se refiere al anclaje territorial como una estrategia de los actores que movilizan recursos materiales e inmateriales impulsados por lógicas económicas y que, en consecuencia, organizan y reorganizan el territorio, pero que, a su vez, son condicionados por este último. Por su parte, Craviotti (2016) utiliza el concepto para analizar conexiones y desconexiones de empresas multinacionales y locales, verticalmente integradas, con el espacio local y sus agentes.
[...], a la búsqueda de la identidad y apoyado en un sistema simbólico" (Cañón, 2014, pp. 10 y 13) y el sentido de pertenencia a un determinado espacio social (Jungemann, 2008) que, en conjunto, condicionan cada decisión y cada acción.

Por su parte, Yolande Riou (2011) sostiene que el anclaje territorial se fundamenta en dos procesos: en primer lugar, se vincula con la manera en que los pobladores de un espacio se apropian del mismo para convertirlo en espacio vivido. Esta apropiación se materializa a través de las prácticas y representaciones de los individuos sobre su espacio y, en segundo lugar, se relaciona con los motivos por los cuales cada habitante se asienta en ese ámbito.

En este marco, es apropiado introducir el concepto de sentido de pertenencia o sentido de lugar, entendido como el "conjunto de sentimientos, percepciones, deseos, necesidades [...] construidos sobre la base de las prácticas y actividades cotidianas desarrolladas en los espacios cotidianos" (Ortiz Guitart, 2004, p. 164); en contraposición se encuentra el desarraigo relacionado con la "ausencia de significados de los lugares y con la pérdida de autenticidad de éstos" (Ortiz Guitart, 2004, p. 163). Lo expuesto se complementa con la idea de Flores Avendaño, quien introduce el concepto de apego relacionado

[...] al "dentro"; este recurre a cosas y personas vistas, encontradas, tratadas o con las que se ha interactuado en la rutina habitual y en la cotidianidad [...] es el lugar donde nadie se encuentra perdido, sin palabras y sin estar seguro de cómo actuar (2010, p. 20).

En esta misma línea de pensamiento, Escalera Reyes (2013) afirma que el apego es un sentimiento 
afectivo fundamental en la conformación del sentido de pertenencia individual como colectivo y una fortaleza para enfrentar conflictos. Además, lo diferencia del concepto de arraigo que se vincula con las maneras de organizar el espacio vivido.

Por su parte, Tuan (2007) sostiene que en la interacción entre el hombre y su entorno se generan vínculos afectivos con diferentes grados de intensidad emocional que crean sentimientos de topofilia - amor y afecto al lugar - o topofobia — rechazo al lugar- Surgen, de este modo, dis- tintas modalidades de vinculación con el espacio vivido que van desde la topofilia intensa - ligada a experiencias placenteras que afianzan el sentido de pertenencia - la toponegligencia - forma de desarraigo al espacio de vida - y la topofobia -relación de rechazo con el entorno-- entre otras (Tuan, 2007; Lindón, 2005).

A manera de síntesis se presenta la Figura 3, en la cual se plasman los aspectos a considerar en el estudio del anclaje territorial teniendo en cuenta los aportes conceptuales citados.

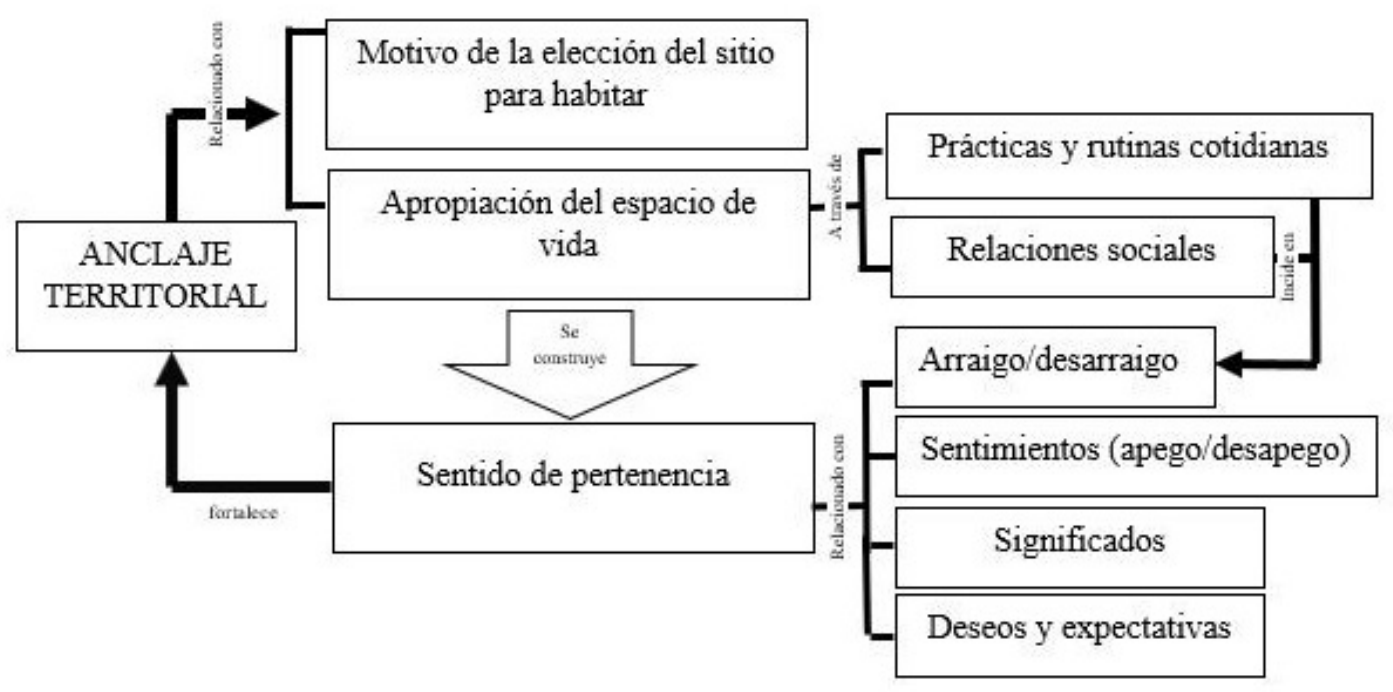

Figura 3. Anclaje territorial: conceptos relacionados

Fuente: elaboración propia con base en Riou (2011), Flores Avendaño (2010), Ortiz Guitart (2004), Jungemann (2008), Cañón (2014) y Escalera Reyes (2013).

En este estudio, entonces, se entiende que el anclaje territorial en el rururbano se construye en el hacer y rehacer de cada habitante en su espacio cotidiano y a través de las prácticas y los vínculos sociales que establece. Este proceso, en definitiva, contribuye a formar el enraizamiento de cada habitante a su espacio vivido tanto desde lo afec- tivo como desde los modos de habitar. Son estos significados arraigados los que pesan a la hora de resistir y adoptar estrategias para permanecer o abandonar el lugar de residencia y que, en consecuencia, incidirán en la tendencia al cambio del borde urbano. 


\section{Resultados y discusión}

\subsection{Caracterización socioespacial del área de estudio: prácticas e interacciones cotidianas en el borde bahiense}

El rururbano bahiense se caracteriza por una ocupación discontinua, edificaciones destinadas a casas de fin de semana con perímetro alambrado y rodeadas de vegetación que conservan los molinos de viento (exponentes rurales en la zona). Estos usos se combinan con terrenos de poca extensión dedicados a la ganadería vacuna, hornos de ladrillo y lotes dispuestos para la venta, evidencia de una posible expansión urbana. Cuenta con servicio de electricidad, sin embargo carece de suministro de gas natural, agua corriente y sistema de desagües cloacales. Así, las aguas subterráneas extraídas mediante bombas o molinos constituyen la principal fuente de suministro y el gas envasado compensa la ausencia de gas natural.

Si bien posee una calidad ambiental y paisajística superior a la de la urbe, la presencia de vertederos incontrolados de residuos sólidos urbanos, en particular en el rururbano noroeste, y la presencia de hornos de ladrillo en el rururbano este alteran y deterioran estas condiciones y se convierten en conflictos ambientales característicos.

En consecuencia, predomina el paisaje rural con una ocupación dispersa, aunque se pueden diferenciar paisajes dominados por la actividad ladrillera, propios de ámbitos fluviales, como otros signados por la decadencia de la actividad agropecuaria intensiva o aquellos donde la ocupación es escasa, pero está en expansión (Figura 4).
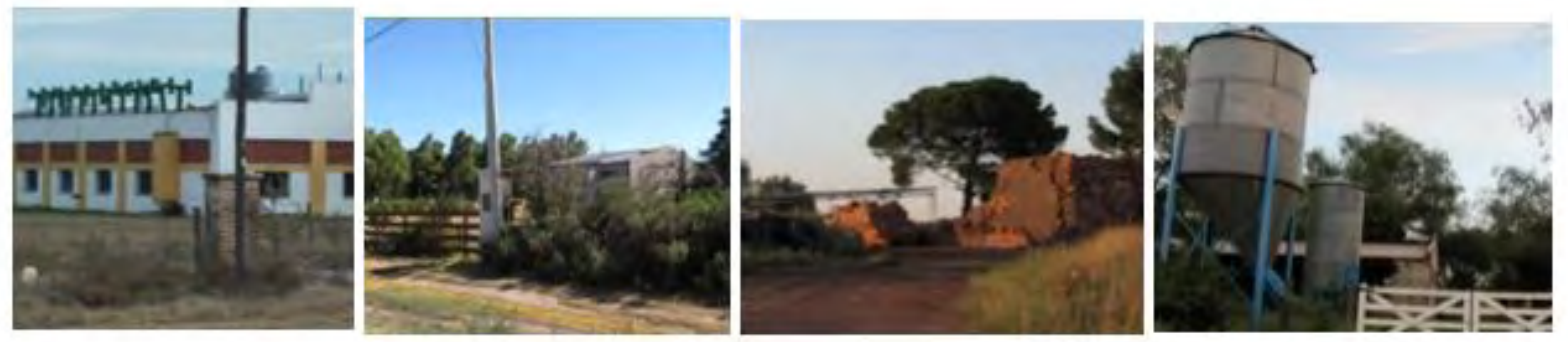

Figura 4. Paisajes heterogéneos en el rururbano bahiense Fuente: fotografías tomadas por la autora entre 2014 y 2015.

Las entrevistas en el área dan cuenta de los distintos residentes según su actividad, tales como los dedicados a actividades agropecuarias - subdivididos entre los que trabajan de manera extensiva y los abocados a tareas intensivas (horticultura, cría de aves, porcinos, equinos o actividades extractivas) -; los que son contratistas y prestan servicios rurales; los antiguos residentes ligados al ámbito rural en su juventud o que actualmente trabajan en campos más alejados del área de estudio y los nuevos habitantes que deciden asentarse en las afueras de la ciudad impulsados por la tranquilidad y el contacto con la naturaleza que ofrece la periferia. La Tabla 1 describe brevemente las características de los entrevistados en el área de estudio. 
TABLA 1. CARACTERÍSTICAS DE LOS RESIDENTES ENTREVISTADOS EN EL RURURBANO BAHIENSE

\begin{tabular}{|c|c|c|}
\hline Actividades & Entrevistado & Caracterización \\
\hline \multirow{4}{*}{$\begin{array}{l}\text { Tareas agropecua- } \\
\text { rias extensivas }\end{array}$} & G. & $\begin{array}{l}\text { Desde que nació vive en el área de estudio (al momento de la entrevista, 2011, tenía } 54 \\
\text { años), es propietario de un campo dedicado en un principio a la actividad lechera y actual- } \\
\text { mente a la cría y engorde de ganado vacuno. }\end{array}$ \\
\hline & F. & $\begin{array}{l}\text { Es propietario del campo desde } 1943 \text { y lo heredó. Actualmente vive con su familia en la } \\
\text { ciudad, pero todos los días van al campo y realizan las tareas de mantenimiento y cuidado } \\
\text { de los animales. Se dedican, en especial, a la cría de ganado vacuno. }\end{array}$ \\
\hline & Lu. & $\begin{array}{l}\text { Son propietarios desde hace más de cuarenta años, su padre y dos socios compraron la } \\
\text { propiedad como lugar de descanso para ganado que vendían en ferias. Actualmente los } \\
\text { campos que poseen en el área de estudio están arrendados. Ellos viven en la ciudad y } \\
\text { trabajan en este ámbito. }\end{array}$ \\
\hline & Dc. & $\begin{array}{l}\text { Propietario desde hace más de treinta años, actualmente se dedica al cultivo de cebada y } \\
\text { ha tenido que vender parte de su propiedad por la cercanía a la ciudad. }\end{array}$ \\
\hline Horticultora & S. & $\begin{array}{l}\text { Arrienda la propiedad desde hace un año (entrevista en 2014). Tiene entre } 25 \text { y } 30 \text { años. } \\
\text { Su padre es horticultor, ella continuó esta actividad y actualmente ambos trabajan en } \\
\text { la explotación. Posee una huerta orgánica y está realizando pruebas con plantación en } \\
\text { invernaderos. }\end{array}$ \\
\hline
\end{tabular}

$\begin{array}{ll}\text { Ella, su esposo y sus dos hijos viven desde el año } 2000 \text { en el predio donde se sitúa la } \\ \text { Granja avícola } & \text { Dlanta de incubación y granja avícola destinada a la distribución de productos en la red de } \\ \text { supermercados Toledo. Desde } 1973 \text { la granja funciona en este predio. Es la esposa del } \\ \text { encargado de la planta de incubación. }\end{array}$

Es propietario desde el 2004, vive con su señora y cuatro niños. Cría chanchos, los vende Criador de cerdos $\quad$ L. $\quad y$, además, reparte leche de campo. Actualmente tiene su propiedad en venta debido a los conflictos que ocasiona el desarrollo de su actividad en un área cada vez más poblada.

\begin{tabular}{|c|c|c|}
\hline \multirow{5}{*}{$\begin{array}{l}\text { Exproductores rura- } \\
\text { les, expropietarios de } \\
\text { guarderías caninas o } \\
\text { dedicados a activi- } \\
\text { dad rural más lejana } \\
\text { del área de estudio }\end{array}$} & C. & $\begin{array}{l}\text { Es maestro mayor de obra jubilado. Desde } 1975 \text { es propietario del lote, pero vive per- } \\
\text { manentemente hace veinte años allí. Su juventud ha estado ligada a tareas rurales, ha } \\
\text { criado chanchos y caballos. Actualmente tiene una quinta para consumo personal y cría } \\
\text { de gallinas. }\end{array}$ \\
\hline & Ms. & $\begin{array}{l}\text { Ella, su esposo y sus tres hijos alquilan la propiedad. Prefieren estos lugares retirados de } \\
\text { la ciudad porque se dedicaron a guarderías caninas años atrás. Actualmente su marido } \\
\text { trabaja en la ciudad. }\end{array}$ \\
\hline & Gr. & $\begin{array}{l}\text { Extrabajadora rural, su marido y ella eran propietarios de un campo en Villa Iris (localidad } \\
\text { de la Provincia de Buenos Aires con } 1.858 \text { habitantes) que tuvieron que vender por ra- } \\
\text { zones económicas. Se trasladaron a Bahía Blanca (1992), donde adquirieron una estación } \\
\text { de servicio en un barrio de la ciudad y compraron una propiedad en el rururbano donde } \\
\text { realizaron prácticas rurales. Actualmente está jubilada y se dedica a realizar tareas artesa- } \\
\text { nales o de jardinería. }\end{array}$ \\
\hline & Mc. & $\begin{array}{l}\text { Hace más de veinte años que son propietarios del lugar, su padre tiene un campo más } \\
\text { alejado del área de estudio y, además, transporta harina para hacer huesos para perros. La } \\
\text { familia residente en la propiedad y se compone por el matrimonio y cuatro hijos. }\end{array}$ \\
\hline & Al. & $\begin{array}{l}\text { Vive en el lugar hace diez años. Su novio se dedica a tareas rurales en un campo cercano } \\
\text { a la ciudad de Bahía Blanca. En su juventud se relacionó con las labores en el campo y } \\
\text { actualmente acompaña a su pareja en las actividades agropecuarias. }\end{array}$ \\
\hline \multirow{2}{*}{$\begin{array}{l}\text { Cuidado equino y prác- } \\
\text { ticas de equitación }\end{array}$} & A. & $\begin{array}{l}\text { Desde } 1994 \text { es administrador de la Asociación de Raids y Turismo Ecuestre del Sur. Traba- } \\
\text { jó durante su juventud en el campo y sus patrones le ofrecieron encargarse del manteni- } \\
\text { miento de este lugar, situación que hizo que se instalara en el predio donde actualmente } \\
\text { reside con su esposa y una de sus hijas. }\end{array}$ \\
\hline & O. & $\begin{array}{l}\text { Desde } 1994 \text { reside en el lugar con su pareja. Se encarga de criar caballos y enseñar } \\
\text { a cabalgar a jóvenes y niños. Asimismo, cría animales, gansos, gallinas y otros animales } \\
\text { domésticos. }\end{array}$ \\
\hline
\end{tabular}

Vol. 25 N. ${ }^{\circ} 2$

julio - diciembre de 2020

pp. 56-79 


\begin{tabular}{|c|c|c|}
\hline Actividades & Entrevistado & Caracterización \\
\hline \multirow{3}{*}{ Prestar servicios rurales } & Pr. & $\begin{array}{l}\text { Él y su esposa viven en el lugar hace cuarenta años. Presta servicios a los trabajadores } \\
\text { rurales y posee un galpón con maquinaria agrícola que pone a disposición de los propie- } \\
\text { tarios de campos cercanos. }\end{array}$ \\
\hline & V. & $\begin{array}{l}\text { Vive allí con su esposa y su hija desde } 1995 \text { y son propietarios. Se crio en el campo, su } \\
\text { abuelo era alambrador y le gusta la vida tranquila. Se dedica a prestar servicios de cons- } \\
\text { trucción en las zonas rurales. }\end{array}$ \\
\hline & Ol. & $\begin{array}{l}\text { Reside hace once años junto con su esposo y sus hijos pequeños en Los Chañares. Su } \\
\text { esposo es contratado por trabajadores rurales para realizar alambrados. De este modo, } \\
\text { su marido se traslada a la zona rural durante la semana y el fin de semana vuelve a su } \\
\text { residencia de Los Chañares. }\end{array}$ \\
\hline \multirow{2}{*}{$\begin{array}{l}\text { Antiguos residen- } \\
\text { tes del área }\end{array}$} & Mu. & $\begin{array}{l}\text { Hace } 26 \text { años que viven en el lugar con sus padres y dos hermanos. La ocupación de sus } \\
\text { padres es en la ciudad de Bahía Blanca. }\end{array}$ \\
\hline & P. & $\begin{array}{l}\text { Ella y su familia (esposo y seis hijos) viven allí desde } 1997 \text {. Adquirieron la propiedad por- } \\
\text { que no les gusta la ciudad y consideran que esta zona es más tranquila para criar a sus } \\
\text { hijos. Su esposo es abogado y trabaja en la ciudad, y ella se dedica a las tareas del hogar. }\end{array}$ \\
\hline \multirow{4}{*}{$\begin{array}{l}\text { Nuevos pobladores } \\
\text { relacionados con ac- } \\
\text { tividades urbanas }\end{array}$} & Ax. & $\begin{array}{l}\text { Él y su esposa son propietarios, pero al momento de realizar la entrevista (2013) no vivían } \\
\text { permanentemente porque aún no estaba terminada la edificación. Eligen este lugar por su } \\
\text { tranquilidad y su paisaje único. Sus prácticas laborales son en la ciudad. }\end{array}$ \\
\hline & Mar. & $\begin{array}{l}\text { Ella y su esposo son propietarios y al momento de la entrevista (2013) Ilevaban un año y } \\
\text { seis meses en el lugar. Ella se dedica a los servicios inmobiliarios. Él es trabajador de un } \\
\text { frigorífico y en su juventud se dedicó a tareas rurales. Ambos son amantes de la tranqui- } \\
\text { lidad y la vida al aire libre. }\end{array}$ \\
\hline & Pl. & $\begin{array}{l}\text { Reside desde } 2009 \text { en el lugar, donde su esposo vivía. Posee un comercio en la ciudad. Le } \\
\text { agrada la tranquilidad y la libertad que existe allí. }\end{array}$ \\
\hline & RF. & $\begin{array}{l}\text { Al momento de la entrevista (2013), hacía un mes que había adquirido la propiedad. La } \\
\text { familia está compuesta por tres integrantes: él, su esposa y un hijo. El lugar era usado para } \\
\text { criar chanchos y RF. desea arreglarlo como vivienda de fin de semana y posteriormente } \\
\text { de estadía permanente. }\end{array}$ \\
\hline \multirow{4}{*}{$\begin{array}{l}\text { Dedicados a hor- } \\
\text { nos de ladrillo }\end{array}$} & An. & $\begin{array}{l}\text { En } 1946 \text { su padre adquirió el terreno, donde construyó una vivienda y se dedicó a fa- } \\
\text { bricar ladrillos. En el lugar residen dos hermanos y sus familias. La actividad ladrillera ha } \\
\text { sido heredada de su padre, aunque también se dedica a hacer tareas de mantenimiento } \\
\text { y construcción. }\end{array}$ \\
\hline & R. & $\begin{array}{l}\text { Es empleado en un horno de ladrillos que hace } 35 \text { años está instalado en el lugar (2013). } \\
\text { Toda su vida se dedicó a esta tarea. }\end{array}$ \\
\hline & LI. & $\begin{array}{l}\text { Es empleado de una distribuidora de ladrillos. Hace doce años que reside en el lugar, } \\
\text { donde se encarga de atender a la gente interesada en los materiales de construcción. }\end{array}$ \\
\hline & B. & $\begin{array}{l}\text { Desde el } 2002 \text { alquilan el lote donde trabajan en hornos de ladrillo y vive con sus sobrinos } \\
\text { en el lugar. Si bien alquilan la propiedad, manejan la producción en la propiedad y contra- } \\
\text { tan trabajadores temporales. La producción es artesanal. }\end{array}$ \\
\hline
\end{tabular}

Fuente: elaboración propia con base en entrevistas realizadas entre 2011 y 2015.

La cotidianidad del espacio rururbano se distingue, en general, por prácticas y rutinas diarias ligadas a las tareas rurales - ya sea agrícola-ganadera intensivas o extensivas o prestación de servicios en los campos - basadas en el amor a la tierra, la historia familiar, el trabajo y el esfuerzo como ejes fundamentales del modo y el ritmo de vida propios del área. Entre las prácticas cotidianas que mencionan en las entrevistas se destacan: arreglar los alambrados y los molinos, atender el ganado y los 
animales de granja, cortar leña, sembrar, comprar insumos en la ciudad y realizar trámites administrativos, entre otras.

La frecuencia de viajes a Bahía Blanca es diaria, especialmente para los que tienen hijos estudiando o venden algún producto fresco y, en algunos casos, entre dos a tres veces por semana. La ciudad es fuente de servicios para la familia y de insumos para los animales, pero además es el centro donde se comercializan los productos.

Los entrevistados constituyen, en su mayoría, pequeños productores y ladrilleros artesanales, predomina el trabajo familiar y solo algunos contratan temporariamente mano de obra. La tecnología que adoptan es limitada, dentro de la cual mencionan el uso del celular, las prácticas de siembra directa, la posesión de un tractor u otra maquinaria para el trabajo agropecuario - máquina para hacer rollos, ordeñadoras o tecnología destinada al manejo de aves - y, además, exponen que la práctica agropecuaria constituye su forma de vida.

Cada palabra y opinión expresada por los entrevistados revela el significado de su propiedad y la carga emocional que los une a estos espacios de vida donde desean permanecer y que quieren mantener para sus hijos y sus nietos. Así, es dable afirmar que predominan sentimientos de topofilia (Tuan, 2007) como muestra del apego y del sentido de pertenencia al lugar. Al contemplar las palabras comunes en los comentarios sobre el significado y los calificativos del lugar, la que más se repite es "tranquilidad", que es un vocablo común en casi todas las entrevistas, tanto de antiguos como de nuevos residentes; a esta se suma la expresión "mi lugar [...] lo que necesito" asociada, en particular, a aquellos pobladores más antiguos.
Se comprueba la hibridez que distingue este borde no solo desde lo espacial, sino también por la interacción de dos estructuras sociales disímiles: una relacionada con los antiguos residentes - dominada por la ruralidad, el amor por la naturaleza y el respeto de sus ciclos, pues son la base de su economía, con relaciones sociales basadas en la solidaridad, la cooperación y la confianza mutua- y otra que conservan los nuevos residentes del área, vinculada a las prácticas urbanas, con un ritmo propio y de preferencia solitaria e individualista. Ambas estructuras coexisten y entre ellas se generan tensiones por las controversias entre los modos de habitar este espacio (Sereno, 2018).

\subsection{Anclaje territorial: ¿una fortaleza para los residentes del rururbano bahiense?}

El avance de la ciudad de Bahía Blanca afecta este espacio y constituye un peligro que expone a los residentes de estos ámbitos de transición a distintos riesgos. Es decir, provoca procesos de transformación 1) en los usos del suelo, puesto que muchos sectores de uso agropecuario se convierten en zonas residenciales, recreativas o industriales y otros establecimientos reconvierten sus funciones; 2) en las formas de vida de la población rururbana porque la llegada de nuevos residentes con ritmos y modos urbanos es percibida como una invasión en este espacio vivido ${ }^{7}$ y como una lógica incompatible con el respeto por la naturaleza, la tranquilidad y la solidaridad propia de estos ámbitos; y

Entendidos como espacios cotidianos, cargados de sentidos similares o diferentes al resto - pluralidades de sentido-, y donde lo simbólico - representaciones, imágenes, significados-y el tiempo, que es el de las prácticas diarias, se enmarca, a su vez, en un tiempo histórico (Di Méo, 1999; Lindón, 2005). 
3) en la configuración espacial, ya que aparecen elementos construidos, tales como viviendas y vías de circulación entre otros que cambian la fisonomía y el paisaje del borde bahiense.

Es en este contexto donde el anclaje territorial juega un papel primordial puesto que condiciona las estrategias de adaptación y permanencia de sus habitantes. Cada residente entrevistado evidencia vínculos afectivos o, por el contrario, desapego con el entorno natural, material y con otras personas.

El análisis de las entrevistas, teniendo en cuenta los aspectos contenidos en la Figura 3, permitió elaborar una tipología de anclajes diferenciados por el motivo de instalación en el rururbano, las prácticas y rutinas cotidianas, el sentido de pertenencia y los significados y vínculos sociales (Tabla 2).

TABLA 2. ANCLAJES TERRITORIALES EN EL RURURBANO BAHIENSE

Motivo de elección de este sitio para vivir
Sus integrantes son los más antiguos en el borde, están o estuvieron ligados a tareas agropecuarias o se dedican a prestar servicios rurales. Este grupo elige el rururbano para habitar porque la mayoría siempre ha residido en este lugar o han estado relacionados con actividades rurales desde su niñez.
Tipo 1. Enamorados del lugar: eligen el rururbano para habitar y desean permanecer allí.

Lo componen residentes dedicados a tareas hortícolas, antiguos residentes del borde, algunos con una antigüedad de más de veinte años en el área.

En ellos se corrobora el amor por las labores en la tierra transmitida de generación en generación. Se sienten ligados a este espacio debido al tiempo de residencia y al esfuerzo empleado para lograr lo que actualmente poseen. La mayoría destaca la similitud del rururbano con el ámbito rural, pero con la ventaja de la accesibilidad a la ciudad.

Las prácticas domésticas de este grupo se conjugan con las laborales. La actividad rural es parte de la vida y de la historia familiar, es decir, trabajo, cotidianidad y espacio de vida se convierten en sinónimos que coinciden en el mismo lugar geográfico (Lindón, 2002). Disfrutan de la naturaleza y sostienen, en algunos casos, un trato amigable con Prácticas y ruti- ella a través de prácticas de reciclaje y disminución de la generación de basura, entre nas cotidianas otras. Sus expectativas se centran en conservar estos ámbitos y rechazan el avance de la ciudad.

La siguiente expresión es un ejemplo de las rutinas cotidianas propias de este grupo:

"Me levanto, le doy comida a las gallinas porque tengo un gallinero [...], a los perros, y después depende [...], sacar yuyos, hacer trasplantes [...], hacer algún pedido porque estoy en contacto con el INTA [...], que me está ayudando también a poder vender [...], y ahora empecé con esto que es un vivero [...], la idea es hacer aromáticas [...], entonces también estoy con eso [...], hacer almácigos, hacer plantines en bandejas, después se trasplanta a macetas [...], este es el tiempo de hacer esto [...], cuando entra el sol termina el día" (S., horticultora en el rururbano noroeste de la ciudad de Bahía Blanca, entrevista realizada en 2014).

El espacio se entiende como mucho más que un soporte físico, puesto que posee una carga simbólica evidente en las expresiones de los entrevistados y en los lazos que entablan con su territorio. Califican el lugar como "todo lo que necesitan para su vida" y no encuentran desventajas de accesibilidad ni de provisión de servicios, como nombran

Sentido de pertenencia y significados otros entrevistados. De este modo, son comunes afirmaciones que dan cuenta del estar aferrado a este espacio y al modo de vida, tales como:

"Es todo... es todo... yo siempre les digo a mis hijas que de acá no me voy más [...] cuando me mudé acá decía 'quizás es medio difícil vivir en un lugar medio aislado' [...], sin embargo, hoy te digo que a la ciudad no voy más, este lugar es para mí, mi familia [...], así que no me voy" (O., residente del rururbano noreste desde hace diez años, entrevista realizada en 2014). 
Vínculos sociales y prácticas de interacción
La red de vínculos se construye con productores agropecuarios, gente asociada al agro en su juventud y prestadores de servicios rurales con los que mantienen lazos familiares y de amistad. Prevalecen las prácticas de interacción basadas en la solidaridad, la amistad y la confianza dado que los vecinos se conocen y ayudan, contrarias a aquellas que predominan en ámbitos urbanos. En algunos casos hay relaciones laborales y contratos de palabra por un período determinado. Las siguientes frases evidencian lo expuesto:

"Nos conocemos todos acá... nos saludamos [...] e incluso, te digo más, nos cuidamos los unos a los otros [...], si vemos algo extraño o raro nos avisamos [...] nos llevamos bien con todos" (A., encargado del mantenimiento en la Asociación Ecuestre, entrevista realizada en 2014).

"[...] como somos pocos, [...] es un poco como un pequeño pueblo [...] de vigilancia, por seguridad [...], intercambios y préstamos de herramientas [...], compartir, tomar mate [...], compartir ideas, buscar cosas en común [...] mejoramiento de algún servicio [...]. Vivimos muy aislados y completamente desprotegidos, [...] hemos tenido problemas de incendios [...], los bomberos llegan cuando ya se quemó todo, [...] así que entre vecinos lo apagamos" $(V$., propietario en el noroeste del rururbano bahiense y prestador de servicios de construcción, entrevista realizada en 2014).
Tipo 2. Evalúan dejar el lugar: si bien eligen el rururbano, evalúan la posibilidad de irse.
Aunque eligen el rururbano para habitar y han creado vínculos sociales y con el lugar que son sólidos, se ven presionados a abandonar su propiedad por practicar actividades que generan molestias o conflictos para los nuevos residentes; en consecuencia, el

Motivo de elección de avance de la ciudad se observa como una amenaza para la continuidad de sus labores. Los entrevistados incluidos aquí se dedican a actividades extensivas o intensivas y no pretenden abandonar estas tareas que han sido transmitidas por generaciones en su familia. Algunos de ellos ya tienen su propiedad en venta.
Prácticas y rutinas cotidianas
La mayoría se ocupa de tareas ganaderas, cría y recría de vacunos, ovejas o cerdos y, en menor medida, se abocan a prácticas agrícolas, especialmente porque el área es marginal y está caracterizada por períodos de sequías. Del mismo modo que el grupo anterior, las prácticas domésticas coinciden con las laborales y se producen en el mismo lugar geográfico. El siguiente párrafo relata las prácticas cotidianas de uno de los residentes con este tipo de anclaje:

"[...] se recorre la hacienda, se ve el estado, si es que hay que hacer un trabajo con la hacienda, se hace [...], darle de comer, destetar los terneros [...]. Es variante, el campo no es una actividad fija que vos decís voy a tal lugar, hago el trabajo y vuelvo. Depende la época, se hacen los trabajos [...]. Si es agricultura, hay que sembrar verdeos, hay que hacer rollos, hay un montón de actividades diferentes, no es que están planificadas, tal día salgo a hacer tal trabajo [...]. Está más o menos clarificado, pero justo ese día se te atraviesa otro problema y salís a hacer otro trabajo. El horario lo pone uno, a veces trabajás horario corrido, a veces se para a comer, no es un horario fijo que se trabaja [...], no tenemos horario" (G., propietario de un campo en la periferia noroeste de Bahía Blanca, entrevista realizada en 2011).
Sentido de pertenencia y significados
Está ligado a la historia familiar de cada residente - en especial de los productores-, quienes heredan el amor por su propiedad y el lugar por las sensaciones agradables que les genera. Sus opiniones evidencian vínculos afectivos con el entorno natural y material y con otras personas a través de las actividades que realizan. A modo de ejemplo, citamos algunas:

"Es una forma de vida [se ríe], hay gente que le gusta la ciudad, a mí me gusta el campo [...], la libertad que tengo en el campo, no sentirme comprimido en una ciudad" (G., propietario de un campo en el rururbano noroeste, entrevista realizada en 2011).

"Pensar en el campo me lleva a sentir amor, amor puro" (Dc., propietario en el rururbano norte, entrevista realizada en 2015). 


Tho de anclaje Categoria de análisis

Los lazos constituyen un capital social que permite acceder a información y recursos y así alcanzar objetivos que de manera individual no se lograrían. De este modo, uno de los entrevistados comenta: "Si no tenés buena relación con los vecinos [...], te morís", y expresa que estos vínculos aún perduran a pesar de que algunos deban abandonar las tareas rurales y asentarse en la ciudad. Son vínculos de amistad, pero también laborales, de cooperación y solidarios, tal como lo muestran las siguientes expresiones:

"Con los del campo tengo muy buena relación de toda la vida [...], muy buena... con los demás, no. [El hecho de que la ciudad se extienda hacia este lado] me genera miedo

Vínculos sociales [...]. Me duele que la ciudad se venga" (Pr., prestador de servicios rurales localizado en el rururbano norte, entrevista realizada en 2013).

"Conozco a todos los vecinos, han ido cambiando, cada vez somos menos los productores que quedamos. El vecino que tenía al lado ya hace años que dejó de producir, el que está en la otra parte del potrero también ya dejó la explotación agropecuaria, el que está en el fondo, cambió de dueño, todavía no lo conozco, pero no tenemos una relación y hay otro vecino que es como yo, que todavía confía en la explotación agropecuaria y nos ayudamos mutuamente" (G., productor agropecuario, desde hace más de cincuenta años reside en el rururbano noroeste, entrevista realizada en 2011).

Tipo 3. Forzados por razones laborales o familiares: no eligen espontáneamente este lugar para habitar, pero permanecen en él.
No han elegido espontáneamente el rururbano para habitar, sin embargo, situaciones familiares o diferentes ofertas de trabajo forzaron su instalación allí. A este grupo le agradan las características del lugar, incluso algunos evalúan la posibilidad de construir una vivienda propia cerca, pero el principal motivo de permanencia es la seguridad laboral que les brinda vivir en el sector. En los casos donde el rururbano constituye el ámbito laboral, la expansión urbana es percibida con resistencia - porque pone en peligro la actividad que los sustenta-, en cambio, para los que se trasladaron por motivos personales, es observada como una ventaja para la obtención de servicios e infraestructura.

Todos los trabajadores de hornos de ladrillo o empleados en la granja avícola entrevistados se encuentran en esta categoría de anclaje. La producción ladrillera es artesanal o semiindustrial. Gran parte de los hornos de ladrillos cuenta con trabajadores de origen boliviano que están contratados, trabajan a destajo o arriendan tierras y comienzan la elaboración de este producto. Las condiciones de vida, laborales y sanitarias observadas son precarias y, en general, el lugar de trabajo y donde se desarrolla la vida cotidiana coinciden. En cuanto a la producción avícola, comprende una planta de incubación, además de la granja avícola. La producción se destina a la cadena de supermercados. La siguiente expresión da cuenta de las rutinas de este grupo:

"Se trabaja por hora [...], las tareas son cortar, apilar, parar al mediodía y luego 14 o 15.30 horas seguís trabajando. [...] se trabaja y cobra por horas trabajadas [...], se carga el ladrillo [...], comienzo a las ocho de la mañana. [...] El 95\% de los ladrillos se vende en la ciudad" (R., empleado de un horno de ladrillos en la periferia este de Bahía Blanca, entrevista realizada en 2013).

Valoran este espacio porque encuentran su fuente laboral y de sustento familiar. Desean permanecer en el lugar, conservar su trabajo y poder progresar en este ámbito. A modo de ejemplo, se mencionan las opiniones de dos de ellos:

Sentido de pertenencia y significados

"Deseo permanecer acá [...], que sea para los hijos nuestros" (An., propietario en rururbano noroeste, exladrillero, entrevista realizada en 2014).

"[...] que continúe la tranquilidad y conservar el trabajo" (D., esposa del encargado de una granja avícola en el rururbano noroeste, entrevista realizada en 2014).

Los vínculos sociales se establecen con fines laborales, en especial por trabajo temporario, así como entre las familias de quienes están empleados en este tipo de tarea. Las expresiones de estos residentes dan cuenta de la vulnerabilidad del sector:

Vínculos sociales "Se hace lo que se puede [...], cada uno elige [...], estamos como podemos [...], depende
de la plata que juntemos, empleamos gente o no" (B., ladrillero que alquila una propiedad en el rururbano este desde 2002, entrevista realizada en 2014). 

Motivo de elección de darlos y administrarlos desde la ciudad. Este grupo no posee lazos afectivos con el este sitio para vivir lugar, sino que la propiedad constituye un bien de capital y en sus decisiones prima la conveniencia económica.

Las prácticas cotidianas de este grupo se realizan en la ciudad. No viven en el rururbano ni lo desean. Presentan una actitud de especulación y esperan que la tierra se valorice

Prácticas y rutipara poder venderla. Así lo expresa uno de ellos:

nas cotidianas_- "La familia nunca vivió en el campo, esto era un acuerdo entre socios, mi padre, su hermano y otro señor más, que tenían varios establecimientos rurales en la provincia de Buenos Aires, traían hacienda a la ciudad de Bahía Blanca" (Lu., propietario de un campo

Tipo 4. No en el rururbano noroeste, entrevista realizada en 2015).

eligen el borde para habitar.
Puesto que son propietarios que no tienen interés en vivir en el rururbano no hay sentimientos de apego, sino que lo consideran un bien económico, tal como lo devela la siguiente expresión:

Sentido de pertenen-__ "La ventaja es que eso el día de mañana va a tener un valor mucho más alto que el valor cia y significados rural, incluso nosotros tenemos proyectado y hemos presentado alguna papelería en la municipalidad para hacer un country, pero tuvimos algunas dificultades con ese tema. Por ahora dejamos que siga aumentando su valor [...] a medida que pasa el tiempo, más urbano se vuelve" (Lu., propietario de un campo en el rururbano noroeste, entrevista realizada en 2015).

Vínculos sociales

Este grupo no presenta vínculos sociales con los residentes del rururbano. Su red de relaciones familiares, de amistad y laborales está construida en la ciudad.
Motivo de elección de este sitio para vivir con la naturaleza, se alejan de la urbe para habitar las periferias de la ciudad. Tienen una antigüedad menor a cinco años y en algunos casos no residen permanentemente en el área.

\begin{abstract}
Reconocen la tranquilidad del lugar y las ventajas de contar con grandes espacios verdes, aunque destacan las desventajas de no disfrutar de agua de red, gas o cloacas. Sus prácticas se vinculan con actividades relacionadas con el funcionamiento de la ciudad y Prácticas y ruti- viajan diariamente a Bahía Blanca, donde desarrollan sus rutinas. Así lo manifiesta uno nas cotidianas de ellos:

"Trabajamos en la ciudad, yo en un frigorífico y mi señora es administradora de propiedades" (Mar., residente urbano desde hace un año y medio en el lugar, entrevista realizada en 2013).
\end{abstract}

Tipo 5. En proceso de construcción de anclaje.

Este grupo está construyendo su red de vínculos con el resto de los residentes y con este espacio a través de distintas prácticas domesticas relacionadas, en general, con el disfrute de la naturaleza y la tranquilidad que brindan estos bordes. Así lo manifiesta Sentido de pertenen- uno de los entrevistados:

cia y significados

"Fue lo primero que tuvimos juntos, lo armamos juntos [...], dentro del poco orden que hay [...] hasta que lo terminemos de armar, hay mucho amor acá adentro [...]. va, Io queremos" (Mar., residente urbano desde hace un año y medio en el lugar, entrevista realizada en 2013).

Los nuevos residentes con mentalidad urbana manifiestan la escasa necesidad de rela-
cionarse con los vecinos y lo placentero de la vida en el interior de sus hogares:
"Parece que no, pero la gente que viene a vivir a estos lugares en el fondo somos me-
dios raros [...], solitarios [...], se mete cada cual en su lugar, atiende sus plantas, atiende
sus cosas, y al vecino [...] 'Hola, qué tal' y nada más. [...] gente muy buena, no están
en el tema del chismerío [...], cada cual se mete en su lugar [...], medianamente hay un
trato cordial con los vecinos" (Mar., residente hace un poco más de un año, entrevista
realizada en 2013).

Fuente: elaboración propia sobre la base de entrevistas realizadas a residentes del rururbano bahiense entre 2011 y 2015.

Vol. $25 \mathrm{~N}^{\circ} 2$

julio - diciembre de 2020

pp. 56-79 
Es llamativo observar la manera en que estos anclajes condicionan las estrategias de adaptación al cambio de los distintos entrevistados, es decir, cada residente, haciendo uso de sus saberes y en un constante hacer y rehacer en sus espacios cotidianos, pone en marcha distintas competencias, resiste y se adapta haciendo acuerdos, implementando tecnologías, recurriendo a las enseñanzas de sus antepasados o al consejo de asesores técnicos, entre otras modalidades de acción; pero, por sobre todas las cosas, transmitiendo a hijos y nietos el amor por las tareas rurales y hacia la propiedad.

La mayoría de estas acciones corresponde a estrategias de sobrevivencia ${ }^{8}$ y algunas son de acumulación ${ }^{9}$, pero en todos los casos constituyen muestras del esfuerzo por conservar este espacio apropiado a través del tiempo y están condicionadas por el anclaje territorial de cada residente.

La Figura 5 permite comparar las estrategias de los entrevistados según el tipo de anclaje territorial. En este sentido, los enamorados del lugar (tipo de anclaje 1 de la Tabla 2) ponen en marcha la mayor cantidad de estrategias de permanencia, tales como apostar por la educación de sus hijos $(9 \%)$, transmitir valores y amor por las labores del agro y por la propiedad a hijos y nietos (39\%) e implementar actividades extraprediales, generalmente no asociadas al agro (22\%). Además, hay algunos que implementan estrategias de acumulación tales como diversificar la actividad dentro

8 Las estrategias de sobrevivencia están asociadas con escasos recursos para enfrentar la situación y persistir en la actividad agropecuaria, lo que obliga a la diversificación en otras actividades (Tacoli, 2003).

9 Las estrategias de acumulación son adoptadas por los grupos más favorecidos porque poseen mayor disponibilidad de capital y de recursos técnicos y financieros que permiten sacar el máximo provecho de los cambios en el área (Tacoli, 2003). de la propiedad $(9 \%)$, incorporar nuevas técnicas (4\%), mantener los vínculos sociales con productores agropecuarios ( $9 \%$ ) y ser creativos, con una actitud alerta hacia los cambios (4\%).

Los entrevistados que evalúan irse del rururbano (tipo de anclaje 2 de la Tabla 2) expresan como modalidades de acción con los mayores porcentajes ( $20 \%$ cada una) la transmisión del amor por el lugar a sus descendientes y la creatividad y la actitud alerta hacia los cambios, y el 17\% decide arrendar otro campo alejado para continuar la actividad agropecuaria - siempre que las posibilidades económicas lo permitan- Luego, casi con valores similares, se encuentran la implementación de actividades extraprediales (13\%), la diversificación de las actividades (13\%) y la incorporación de nuevas técnicas (12\%).

Es oportuno mencionar que, en general, los habitantes comprendidos en la primera y la segunda categoría de anclaje están dedicados a actividades productivas extensivas o intensivas, ambos grupos reúnen a los residentes con más cantidad de años en el rururbano y expresan tener un vínculo fuerte con el lugar y con los demás pobladores del área, aunque los segundos, dados los conflictos que ocasiona continuar con su actividad productiva, consideran abandonar la propiedad y trasladarse a otro sitio. Las estrategias con mayores porcentajes en ambos grupos son evidencia del arraigo y el amor al lugar. Este grupo presenta un anclaje territorial desde los sentimientos y emociones, pero también desde lo económico, si bien en la clase 2 prima lo económico.

Una situación contraria resulta de analizar las estrategias de los forzados por razones familiares o laborales (tipo de anclaje 3 de la Tabla 2), ligados al rururbano desde lo económico y donde la prin- 
cipal estrategia está centrada en la conservación de su trabajo y la necesidad de adaptarse teniendo en cuenta los recursos materiales y las exigencias del empleador (38\%), así como tener una actitud creativa y alerta a los cambios $(25 \%)$.

En una situación similar están aquellos que no eligen el rururbano para habitar (tipo de anclaje 4 de la Tabla 2). Sus estrategias están relacionadas con la especulación, esperan que la propiedad se valorice para poder venderla $(20 \%)$ o a presentar proyectos urbanos dentro de la propiedad (20\%), además de implementar nuevas técnicas, diversificar la producción y ser creativos (con un 20\% cada una). Todas ellas apuntan a optimizar ganancias y, en algunos casos, favorecen la expansión urba- na. En este caso particular existe un "desanclaje" desde lo afectivo y lo emocional hacia el espacio, al cual se encuentran ligados solo por intereses económicos $\mathrm{y}$, en consecuencia, las modalidades de adaptación que implementan son respuestas al desarraigo.

Otro caso singular se observa en los nuevos residentes que se han caracterizado en "proceso de construcción de anclaje" (tipo de anclaje 5 de la Tabla 2) o en un proceso de "reanclaje", puesto que se inician en la generación de lazos sociales y con el espacio debido al poco tiempo de residencia en este ámbito, si bien lo hacen de un modo particular porque conservan vínculos con la ciudad donde trabajan.

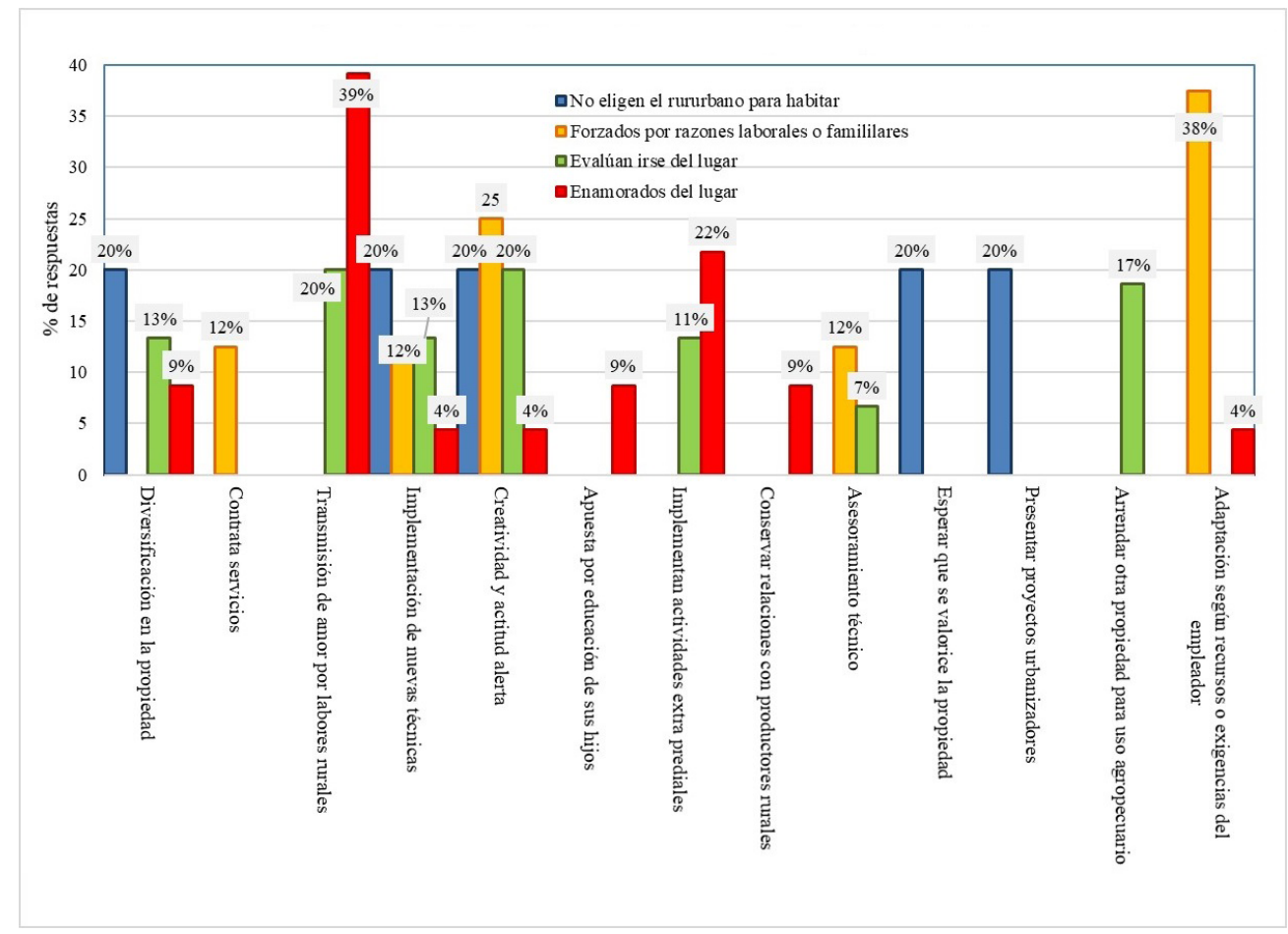

Figura 5. Estrategias de los residentes del rururbano según su anclaje territorial ${ }^{10}$

Fuente: elaboración propia con base en entrevistas a residentes del rururbano realizadas entre 2010 y 2015.

10 La figura no incluye los residentes en proceso de construcción de anclaje porque este tipo de anclaje territorial corresponde a los nuevos residentes que no implementan estrategias de resistencia a la urbanización. 
En este panorama descrito se observa la correspondencia entre el tipo de anclaje territorial, el tiempo de residencia, la actividad que practican y las estrategias puestas en marcha para permanecer en el lugar, que sumados permiten reconocer que existe una relación directa entre aquellos que están dedicados a tareas relacionadas con el agro - intensivas, extensivas o prestadores de servicios rurales-, con más de 20 años de antigüedad en el rururbano - y algunos más de 30 y 40 años en el área-, y los que están enamorados del lugar con la menor disposición al cambio.

La resistencia a perder su predio - debido a la incompatibilidad de sus actividades y rutinas con el uso residencial que se encuentra en expansiónes una constante, situación que denota sentimientos de pertenencia y es fundamental para tener un papel activo que favorezca la permanencia.

\section{Reflexiones finales}

Sin duda el estudio de los espacios de transición constituye un desafío, dada la complejidad de las relaciones, intereses y actores que deciden y actúan, y por los procesos que tienen lugar en estos ámbitos, que repercuten en la singular organización y dinámica de los mismos. En este marco, los enfoques de la geografía que ponen en valor y focalizan su mirada en la dimensión sensible del espacio contribuyen para acercarse al estudio de la microescala y a las relaciones de cada individuo con sus pares y con el espacio rururbano en particular, así como con otros espacios (Lindón \& Hiernaux, 2010; Bailly \& Ferrier, 1996).

Este trabajo, entonces, constituye un aporte desde esa mirada, que pone de relieve el concepto de anclaje territorial $-\mathrm{y}$ las dimensiones que inclu- ye su estudio - para revelar lo que impulsa, muchas veces, las acciones de los habitantes de un área particular. Este anclaje vinculado al sentido de lugar, por lo general invisible o no valorado por agentes inmobiliarios, municipales o empresarios que pretenden extender sus proyectos en estos espacios transicionales, es el que moviliza a la hora de adoptar estrategias focalizadas en la continuidad o no en el área y que, en consecuencia, incidirá en las dinámicas socioespaciales y la tendencia al cambio del borde.

El trabajo presentado da cuenta de las especificidades de cada tipo de anclaje territorial y su relación con las modalidades de acción ante el avance urbano en el rururbano bahiense, y permite vislumbrar que en muchos habitantes este sentimiento de amor y apego al lugar constituye una fortaleza para enfrentar los cambios e implementar modalidades de adaptación, pero tendientes a conservar su propiedad y actividad, al contrario de otros, que no presentan lazos afectivos pero mantienen la propiedad por intereses económicos y, en consecuencia, sus acciones persiguen optimizar las rentas. Entre estas dos posiciones opuestas aparecen residentes con tipologías de anclaje que combinan, en distinto grado, aspectos de las antes citadas.

Este estudio, lejos de agotarse, genera nuevos interrogantes, tales como ¿de qué manera se establecerán los vínculos entre los antiguos pobladores y los nuevos? ¿Cuáles son las características del proceso de construcción de anclaje de los nuevos residentes y qué incidencias tienen sus anclajes urbanos previos? ¿Se considerarán, desde los organismos de planificación, los intereses del grupo más antiguo en el área de estudio? ¿Qué encuentros y desencuentros surgirán entre los nuevos y los antiguos pobladores del área? ¿De qué manera 
inciden los cambios globales y cómo los anclajes territoriales influyen en las estrategias adoptadas frente a esto? Todos ellos abren futuras líneas de indagación del rururbano bahiense, pero aplicables también a otros espacios de borde, tendientes a profundizar el estudio y alcanzar un conocimiento integral y más acabado sobre lo que moviliza las prácticas y las estrategias, así como sobre las maneras de intervención en el mismo. 


\section{Referencias}

Arango Escobar, G. (2008). Salvemos el espacio rururbano colombiano. Cuadernos de Vivienda y Urbanismo, 1(2), 394-409. https://revistas.javeriana.edu.co/index.php/ cvyu/article/view/5499/4310.

Arriaga Rodríguez, J. C. (2012). El concepto de frontera en la geografía humana. Perspectiva Geográfica, 17, 71-96. doi.org/10.19053/01233769.2263.

Avalle, G. (2009). Clases y territorio: construcción de subjetividades en los movimientos sociales Avá, Revista de Antropología, 14, 1-19.

Ávila Sánchez, H. (2009). Periurbanización y espacios rurales en la periferia de las ciudades. Estudios Agrarios, 41, 93-123. pa.gob.mx/publica/rev_41/ANALISIS/7\%20 HECTOR\%2OAVILA.pdf.

Bailly, A. \& Ferrier, J. (1986). Savoir lire le territoire: plaidoyer pour une géographie régionale attentive à la vie quotidienne. Espace Géographique, 15(4), 259-264.

Ballén-Velásquez, L. M. (2014). “Desbordando” la categoría de borde. Reflexiones desde la experiencia bogotana. Bitácora Urbana, 24(2), 31-41.

Barros, C. \& Zusman, P. (2001). El lugar de las fronteras. Ayer y hoy en la constitución de territorios de encuentro y desencuentro. En Anuario de la División Geografía 20002001 (pp. 19-31). Dpto. de Ciencias Sociales de la Universidad Nacional de Luján.

Barsky, A. (2005). El periurbano productivo, un espacio en constante transformación. Introducción al estado del debate, con referencias al caso de Buenos Aires. Scripta Nova, 194(36). http://www.ub.es/geocrit/sn/sn-194-36.htm.

Cañón, S. (2014). El anclaje territorial y la construcción del discurso para la recuperación del yacón en Bárcena/Chorrillos, Quebrada de Humahuaca. Ponencia presentada en las IX Jornadas de Estudios Sociales de la Economía, Buenos Aires, Argentina. https://doi.org/10.13140/2.1.2657.9206.

Craviotti, C. (2016). Anclaje, dinámicas e impactos territoriales de la cadena global de cítricos en el nordeste argentino. Anales de Geografía de la Universidad Complutense, 36(2), 259-279. doi.org/10.5209/AGUC.53585.

De Mattos, C. (1999). Santiago de Chile, globalización y expansión metropolitana: lo que existía sigue existiendo. Revista Eure, 35(77), 29-56. https://www.eure.cl/index.php/ eure/article/view/1217/314.

Di Méo, G. (1999). Géographies tranquilles du quotidien. Une analyse de la contribution des sciences sociales et de la géographie à l'étude des pratiques spatiales. Cahiers de Géographie du Québec, 43(118), 75-93. https://www.erudit.org/fr/revues/cgq/1999v43-n118-cgq2690/022788ar/.

Escalera Reyes, J. (2013). "Amor a la tierra": identidades colectivas y resiliencia de los socioecosistemas. En E. Ruiz Ballesteros \& J. L. Solana Ruiz (eds.), Complejidad y ciencias sociales (pp. 333-378). UNIA. https://dspace.unia.es/bitstream/ handle/10334/3620/2013_complejidad_978-84-7993-231-2.pdf. 
Feito, M. (2018). Problemas y desafíos del periurbano de Buenos Aires. Estudios Socioterritoriales, Revista de Geografía, 24, 1-19. https://ri.conicet.gov.ar/ handle/11336/97356.

Flores Avendaño, I. (2010). Un recorrido teórico a la territorialidad desde uno de sus ejes: el sentimiento de pertenencia y las identificaciones territoriales. Inter.c.a.mbio sobre Centroamérica y el Caribe, 7(8), 13-35. https://revistas.ucr.ac.cr/index.php/intercambio/ article/view/3063.

Formiga, N. (1997). Transformaciones recientes en el espacio periurbano de Bahía Blanca. Revista Interamericana de Planificación, 29(114), 119-131.

Frayssignes, J. (2005). Les AOC dans le développement territorial. Une analyse en termes d'ancrage appliquée aux cas français des filières fromagères. [Tesis doctoral, Institut National Polytechnique de Toulouse]. http://ethesis.inp-toulouse.fr/archive/00000550/.

García Ballesteros, A. (1992). Geografía y humanismo. Oikos-Tau.

García Ramón, M. D., Tulla, A. \& Valdovino, N. (1995). Geografía rural. Barcelona: Síntesis.

Giddens, A. (1993). Consecuencias de la modernidad. Alianza.

González Escobar, L. F. (2003). Estrategias corregimentales ECO: políticas para la nueva ruralidad en Medellín. Ponencia presentada en el Seminario Internacional Mundo Rural: transformaciones y perspectivas a la luz de la nueva ruralidad, 14-17 de octubre, Bogotá, Colombia. http://webcache.googleusercontent.com/ search?q=cache:pGHsMuORV4kJ:www.bdigital.unal.edu.co/3368/1/LFG01-ECO. $p d f+\& c d=1 \& h|=e s \& c t=c| n k \& g \mid=c o$.

González Plazas, J. (2006). Caracterización socioespacial actual del hábitat en la periferia urbana de Manizales. Revista de Arquitectura El Cable, 5, 7-25. https://revistas.unal.edu. co/index.php/elcable/article/view/1246.

Hiernaux, D. \& Lindón, A. (2008). El trabajo de campo experiencial y el replanteamiento de la periferia metropolitana. Una interpretación socio-espacial de la economía popular periférica. Revista Internacional de Sociología, 66(50), 215-236. https://doi.org/10.3989/ ris.2008.i50.102.

Instituto Nacional de Estadística y Censos (INDEC). (2014). Provincia de Buenos Aires por partido. Población total. Año 2010. https://www.indec.gob.ar/ftp/cuadros/poblacion/ censo2010_tomo1.pdf.

Instituto Nacional del Agua. (2002). Atlas digital de recursos hídricos superficiales de la República Argentina. [Disponible en CD]. Subsecretaría de Recursos Hídricos.

Jungemann, B. (2008). Organizaciones sociales y anclaje territorial escenarios y componentes de la transformación socioterritorial y local en Venezuela. Cuadernos del Cendes, 25(67), 1-34. http://www.redalyc.org/pdf/403/40306702.pdf.

Lindón, A. (2005). Figuras de la territorialidad en la periferia metropolitana: topofilia y topofobias. En R. Reguillo \& M. Godoy (coord.), Ciudades translocales: espacios, flujo, representación. Perspectivas desde las Américas (pp. 145-172). Instituto Tecnológico y de Estudios Superiores de Occidente (ITESO).

Vol. $25 \mathrm{~N}^{\circ} 2$ 
Lindón, A. (2002). Trabajo, espacios de vida y cotidianidad. La periferia oriental de la ciudad de México. Scripta Nova, 6(119). http://www.ub.edu/geocrit/sn/sn119-56. htm.

Lindón, A. \& Hiernaux, D. (Dirs.) (2010). Los giros de la geografía humana. Desafíos y horizontes. Universidad Autónoma Metropolitana, Anthropos.

Martínez Borrego, E. (2006). Nueva relación rural-urbana: globalización y transformaciones socioespaciales en los Altos de Morelos, México. Ponencia presentada en el VII Congreso de la Asociación Latinoamericana de Sociología Rural (Alarsu), Quito, Ecuador. http://www.alasru.org/cdalasru2006/24\%20GT\%20ESTELA\%20 MARTINEZ\%2OBORREGO.pdf.

Municipalidad de Bahía Blanca. (2011). Plan Director del Periurbano Bahiense y desarrollo de centros de interés turístico ambiental en el partido de Bahía Blanca. MBB.

Municipalidad de Bahía Blanca. (2009). Plan de Desarrollo local Bahía Blanca. Estudio 1. EE 289. Informe final, consultor $n^{\circ} 7$ Susana Zinger. MBB.

Ortiz Guitart, A. (2004). Reflexiones en torno a la construcción cotidiana y colectiva del sentido de lugar en Barcelona. Polis: Investigación y Análisis Sociopolítico y Psicosocial, 1, 161-183. http://www.redalyc.org/pdf/726/72610409.pdf.

Reboratti, C. (1990). Fronteras agrarias en América Latina. Scripta Vetera, 87. http://www. ub.es/geocrit/sv-26.htm.

Riou, Y. (2011). Représentations, participation, ancrage, identité: quatre piliers pour penser l'inscription territoriale. Le cas du Berry. [Tesis doctoral, Université d'Orléans]. https:// tel.archives-ouvertes.fr/tel-00730366.

Sánchez Ayala, L. (2015). De territorios, límites, bordes y fronteras: una conceptualización para abordar conflictos sociales. Revista de Estudios Sociales, 53, 175-179. https:// journals.openedition.org/revestudsoc/9399.

Sereno, C. (2018). El rururbano de la ciudad de Bahía Blanca, provincia de Buenos Aires, Argentina: cotidianidad en un espacio de borde. InterEspaço, 4(5), 260-287. http:// dx.doi.org/10.18764/2446-6549.v4n15p260-287.

Tacoli, C. (2003). Impactos obre los modos de vida y estrategias económicas en la interfase periurbana: un relevamiento de los temas de debate. Cuadernos del Cendes, 20(53), 39-49. http://ve.scielo.org/scielo.php?script=sci_arttext\&pid=S101225082003000200004\&lng=es\&tlng=es.

Tuan, Y. (2007). Topofilia. Un estudio de las percepciones, actitudes y valores sobre el entorno. (Traducción de Flor Durán de Zapata. Título original: Topophilia. A study of environmental perception, attitudes and values). Melusina.

Urriza, G. (2003). El mercado del suelo urbano en Bahía Blanca, Argentina. La consolidación de un modelo de crecimiento urbano de diferenciación espacial. [Tesis de maestría, Pontificia Universidad Católica de Chile]. 
Urriza, G. (2018). Expansión urbana en ciudades intermedias de crecimiento demográfico bajo: el caso de Bahía Blanca, Argentina. EnX Seminario Internacional de Investigación en Urbanismo, Barcelona-Córdoba. DUOT. https://revistes.upc.edu/index.php/SIIU/ article/view/9151.

Zinger, S., del Pozo, O. \& de Gaetano, R. (1990). Bahía Blanca: análisis de la aptitud del medio natural para la expansión urbana. Revista Universitaria de Geografía, 4(1-2), 76-96.

Zuluaga Sánchez, G. P. (2005). Dinámicas territoriales en frontera rural-urbana en corregimiento de Santa Elena, Medellín. [Tesis de maestría, Universidad Nacional de Colombia, sede Medellín]. https://repositorio.unal.edu.co/handle/unal/8407. 